\title{
Superior Mesenteric Artery Syndrome: First Chadian Observation
}

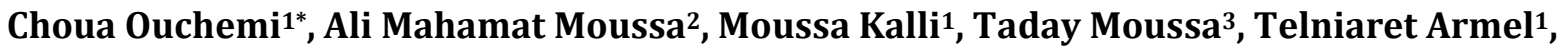 \\ Sadie Ismael Guire' ${ }^{1}$, Sani Rachid ${ }^{4}$
}

\author{
${ }^{1}$ Service de Chirurgie Générale, Hôpital Général de Référence Nationale (HGRN), N’Djaména, Tchad \\ ${ }^{2}$ Service de Médecine Interne et Gastroentérologie, Hôpital Général de Référence Nationale (HGRN), N’Djaména, Tchad \\ ${ }^{3}$ Service de Radiologie, Hôpital Général de Référence Nationale (HGRN), N’Djaména, Tchad \\ ${ }^{4}$ Université Abdou Moumouni, Niamey, Niger \\ Email: *choualori@hotmail.com
}

How to cite this paper: Ouchemi, C., Moussa, A.M., Kalli, M., Moussa, T., Armel, T., Guire, S.I. and Rachid, S. (2017) Superior Mesenteric Artery Syndrome: First Chadian Observation. Surgical Science, 8, 358-364. https://doi.org/10.4236/ss.2017.88039

Received: July 4, 2017

Accepted: August 18, 2017

Published: August 21, 2017

Copyright $\odot 2017$ by authors and Scientific Research Publishing Inc. This work is licensed under the Creative Commons Attribution International License (CC BY 4.0).

http://creativecommons.org/licenses/by/4.0/

(c) (i) Open Access

\begin{abstract}
Introduction: The extrinsic compression of the third portion of the duodenum between the superior mesenteric artery and the aorta defines superior mesenteric artery syndrome. It determines an acute or chronic high intestinal obstruction pattern. We report the first observed case in Chad. Observation: $\mathrm{HH}$ was a 19 year-old woman with abdominal pain and intermittent postprandial vomiting since she was 5 years old. During last 11 months, postprandial vomiting was more frequent, and non resolved after medical treatment. Unquantified weight loss was reported. Body mass index at hospitalization was 9.8. An injected abdominal scan demonstrated significant gastroduodenal distension, upstream of a stenosis of the third duodenal portion. Aorto-mesenteric space and angle were reduced. At laparotomy internal derivation by duodenojejunostomy was done. Postoperative situation was uneventful. Conclusion: Superior mesenteric artery syndrome determines an acute or chronic intestinal obstruction. Injected abdominal scan is fundamental for diagnosis. The treatment is firstly conservative but the need of surgery is common.
\end{abstract}

\section{Keywords}

Superior Mesenteric Artery Syndrome, Intestinal Obstruction, Duodenojejunostomy, Chad

\section{Introduction}

The superior mesenteric artery syndrome (SMA) or Wilkie syndrome is the extrinsic compression of the third portion of the duodenum between the superior 
mesenteric artery and the aorta. It is a rare cause of benign duodenal obstruction with a prevalence ranging from $0.013 \%$ to $0.3 \%$ [1] [2]. Many different debases claiming weight loss represent risk groups of SMA. We can thus cite: cancer, bariatric surgery, chronic infections and severe burns. Some congenital causes are also considered, as shorten Treitz ligament or abnormal origin of superior mesenteric artery. Others high risk conditions are anatomical changes due to surgical procedures such as scoliosis correction and esophagectomy. We report the first case of superior mesenteric artery syndrome in Chad and discuss the etiopathogenic aspects, the diagnostic and therapeutic means.

\section{Observation}

Miss $\mathrm{H} \mathrm{H}$, aged 19, was hospitalized on 10/04/2017 in the gastroenterology department for abdominal pain associated with postprandial vomiting and uncalculated emaciation of progressive installation. This symptomatology had evolved since the patient was 5 years old. She was salutary treated by prokinetics. In the last eleven months, abdominal pain and postprandial vomiting were more frequent and had motivated a previous hospitalization in the same service three months previously. The transit was preserved.

On physical examination, the patient was undernourished, with a body mass index (BMI) of $9.8 \mathrm{~kg} / \mathrm{m}^{2}$. The palpation of the abdomen noted a splash in the epigastric region and cutaneous dehydration folds. The biological assessment did not revealed ionic disorders or renal insufficiency.

The standard x-ray of the abdomen (Figure 1) showed a voluminous clarity drawing the contours of the stomach (dilatation of the gastric air sac) with the presence of air-fluid levels in the right flank and the right iliac fossa.

Upper digestive endoscopy revealed significant gastric and duodenal stasis. The gastroduodenal transit (Figure 2) noted a stenosis of the third portion of the duodenum (D3). An injected abdominal scan confirmed the extrinsic compression of D3. The aorto-mesenteric angle was $13.8^{\circ}$ and the aorto-mesenteric distance was $5.8 \mathrm{~mm}$ in height (Figure 3 and Figure 4). Medical treatment combining correction of dehydration, cessation of oral feeding, and digestive aspiration was initiated. Surgical indication was made; patient's written consent was obtained for surgery and the anonymous use of data for studies. At laparotomy, we performed a latero-lateral duodenojejunostomy between the third distended duodenal portion (D3) and the first jejunal loop (Figure 5). The postoperative course was uneventful with a resumption of feeding on the fourth day and exit on day eight. The patient was seen at clinical control at one month. She was asymptomatic, with a body mass index of $19 \mathrm{~kg} / \mathrm{m}^{2}$.

\section{Discussion}

The superior mesenteric artery syndrome was reported for the first time by Rokitanski in 1861. Wilkie described the pathophysiology and treatment from a series of 64 patients in 1927. This syndrome received many designations over the 


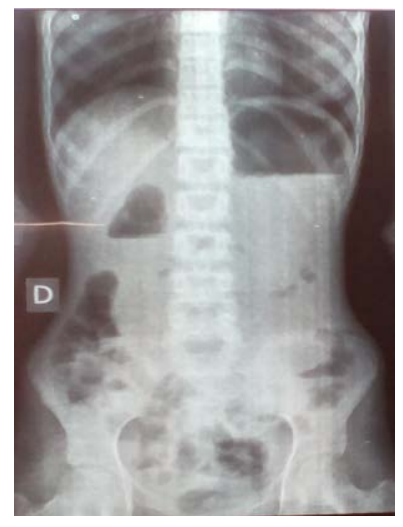

Figure 1. Standard x-ray of the abdomen showing dilatation of gastric air sac. Presence of air-fluid levels in right flank and right iliac fossa.

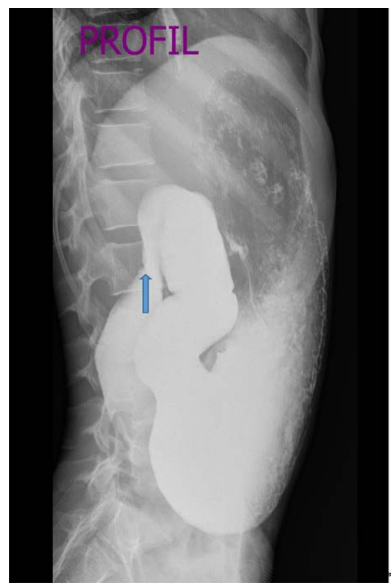

Figure 2. Gastroduodenal transit, lateral projection: gastric and duodenal dilatation among of third duodenal portion stenosis (arrow).

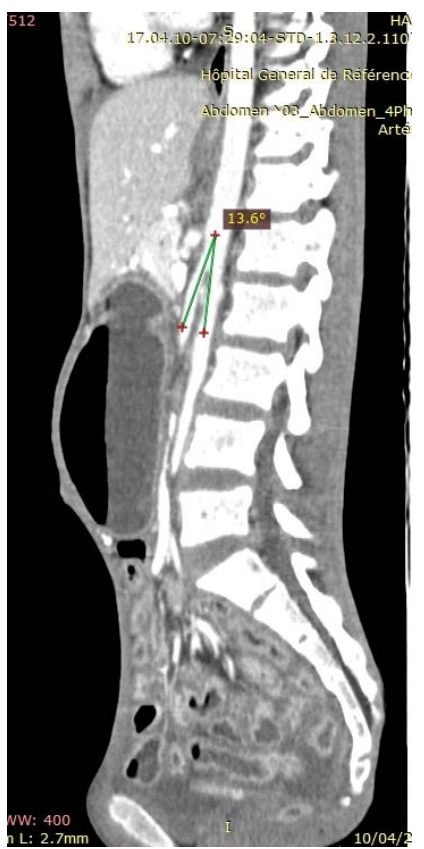

Figure 3. Sagittal injected CT scan with measure of aorto-mesenteric angle $\left(13.8^{\circ}\right)$. 


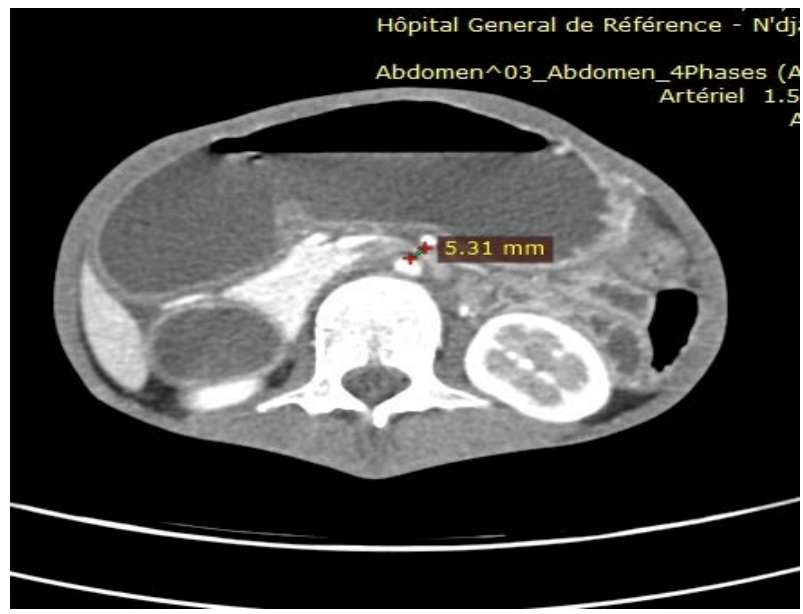

Figure 4. Injected CT scan, axial section showing dilatation of the stomac and duodenum. Measure of the aorto-mesenteric distance $(5.31 \mathrm{~mm})$.

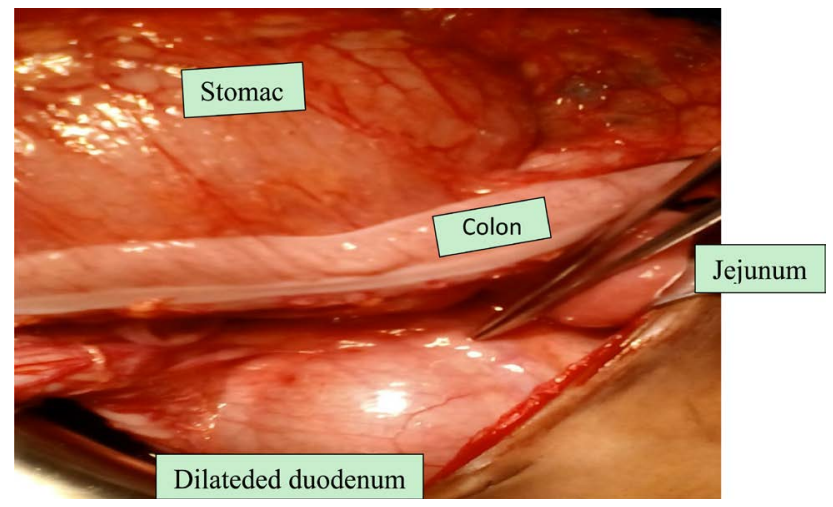

Figure 5. Intraoperatory view showing dilatation of the stomac and duodenum and normal dimension jejunum. The pince shows superior mesenteric vessels.

years: mesenteric forceps syndrome, Wilkie's syndrome, duodenal arterio-mesenteric compression syndrome [1] [2] [3]. The syndrome is related to a reduced aorto-mesenteric space, less than $8 \mathrm{~mm}$ in the third duodenum associated with aortic mesenteric angle less than $22^{\circ}$. Normally, the thickness of the adipose tissue surrounding the superior mesenteric artery (SMA) at its origin allows this angle to be maintained and protects the duodenum from vascular compression [3] [4]. Some favorable factors have been described, including: rapid weight loss leading to melting of mesenteric fat or spinal deformity (hyperlordosis, trauma). This mechanism projects the aorta forward, thereby reducing the exit angle of the superior mesenteric artery. Anatomical abnormalities such as a shortness or hypertrophy of the ligament of Treitz, or a low origin of the SMA would also be incriminated. Identified surgical causes include spinal surgery, abdominal aorta and bariatric surgery, as well as ileo-anal anastomosis. Other etiologies are also found: eating disorders (anorexia nervosa, intestinal malabsorption) and various cache sizing conditions (neoplasias, AIDS, poly traumatism, burns). A genetic factor has recently been incriminated after the description of a superior mesenteric syndrome in members of the same family [1] [3] [4]. 
In this observation, none of these anomalies were found. It is presumably a primitive form in an otherwise constitutionally lean patient. Females aged between 10 to 40 years are more commonly affected as in our report [5].

The clinical expression of superior mesenteric syndrome can be of two clinical types: acute or more often chronic ( $90 \%$ of cases). The acute form is revealed as a high digestive obstruction with possible appearance of complications (hydro-electrolyte disorders, severe respiratory complications or even gastric ruptures). Nephrologic complications by compression of the left renal vein with proteinuria, haematuria and arterial hypertension have also been reported [6]. When the syndrome is chronic, there is intermittent post-prandial epigastric pain with gastric fullness (classically improved by left or ventral lateral decubitus), nausea or vomiting with often reflux symptoms increased by stasis [4]. In our observation, the clinical picture is chronic and all these signs are found. We also note an epigastric dilatation, and slimming.

The diagnosis of certainty is made by medical imaging. Standard radiography confirms high obstruction. Gastroduodenal transit revealed indirect signs of gastric and duodenal dilatation with incomplete linear stop of the contrast at D3 (Figure 2) [4] [5] [6] [7]. Contrast-enhanced computer tomography or magnetic resonance angiography enables visualization of the vascular compression of the duodenum and precise measurement of the aorto-mesenteric angle and distance. It regains a duodenal dilatation upstream of the obstacle and allows to measure the distance between the aorta and the SMA. Normally this distance is 10 to 28 $\mathrm{mm}$ and the aorto-mesenteric angle is between $45^{\circ}$ and $60^{\circ}$. In the case of superior mesenteric syndrome, the angle is closed and measures 6 to $15^{\circ}$ and the distance between the aorta and the SMA is less than $8 \mathrm{~mm}$ [1] [7] [8]. In our observation, the aorto-mesenteric angle and the aorto-mesenteric distance calculated on the images of the CT were respectively $13.8^{\circ}$ and $5.8 \mathrm{~mm}$.

Duodenal obstruction causes a state of acute dehydration and aggravates undernutrition, which maintains a vicious circle that the treatment aims to break [9]. In this observation, chronic presentation and alternated general state didn't permit initial diagnosis. In fact, it was only during the second hospitalization that important weight loss and persisting abdominal pain induced to realize an injected abdominal CT.

The treatment is primarily conservative. It is based on the placement of a naso-gastric tube left in gentle suction, correction of hydro-electrolytic disorders and parenteral nutrition, or better through nasogastric tube [2] [3] [4]. Postural treatment (left lateral decubitus, pro cubitus) only improves symptomatology in $50 \%$ of cases [4]. Surgery is indicated in case of failure of conservative treatment. In reality, it is necessary in every quarter [5] [6] [8], as in our patient. The chronicity of the clinical picture, unavailability of enteral treatment in our context, and the random results of the postural treatment has made us opt for a surgical cure.

The surgical treatment consists of either a derivation by gastrojejunostomy or 
duodeno-jejunostomy [1] [4] [7], or modify the anatomical conditions by making a mobilization and decroise of the duodeno-jejunal angle after section of the muscle of Treitz according to the Strong process. Gastrojejunostomy increased postoperative complication like blind loop syndrome and recurrence of symptoms [1] [6].

Our choice has gone to duodeno-jejunostomy because it is simple to perform, and provides satisfactory results in $80 \%-100 \%$ of cases [1] [3] [4] [7]. We performed it by laparotomy. After two months of follow-up, the patient is asymptomatic and the BMI is $19 \mathrm{~kg} / \mathrm{mm}^{2}$, so the prognosis seems good. Some teams practice laparoscopic duodenojejunostomy. It has the advantage of reducing postoperative pain, length of hospitalization and postoperative hernia [2] [9] [10] [11].

\section{Conclusion}

Superior mesenteric artery syndrome can occur at any age. It is necessary to think of it in front of any high obstruction in a patient with severe weight loss. Injected abdominal CT facilitates diagnosis. Treatment is primarily conservative but need of surgery is common.

\section{References}

[1] Welsch, T., Büchler, M.W. and Kienle, P. (2007) Recalling Superior Mesenteric Artery Syndrome. Digestive Surgery, 24, 149-156. https://doi.org/10.1159/000102097

[2] Le Moigne, F., Lamboley, J.L., Vitry, T., et al. (2010) Superior Mesenteric Artery Syndrome: A Rare Etiology of Upper Intestinal Obstruction in Adults. Gastroenterologie Clinique et Biologique, 34, 403-406. https://doi.org/10.1016/j.gcb.2010.04.012

[3] Barchi, L.C., Alves, A.M., Jacob, C.E., et al. (2016) Favorable Minimal Invasive Surgery in the Treatment of Superior Mesenteric Artery Syndrome: Case Report. International Journal of Surgical Case Report, 29, 223-226. https://doi.org/10.1016/j.ijscr.2016.09.016

[4] Kadji, M., Naouri, A. and Bernard, P. (2006) Superior Mesenteric Artery Syndrom: A Case Report. Annales de Chirurgie, 131, 389-392. https://doi.org/10.1016/j.anchir.2005.12.013

[5] Salem, A., Al Ozaibi, L., Nassif, S.M., Osman, R.A., Al Abed, M.S. and Badri, F.M. (2017) Superior Mesenteric Artery Syndrome: A Diagnosis to be Kept in Mind (Case Report and Literature Review). International Journal of Surgery Case Reports, 34, 84-86. https://doi.org/10.1016/j.ijscr.2017.03.018

[6] Zaraket, V. and Deeb, L. (2015) Wilkie's Syndrome or Superior Mesenteric Artery Syndrome: Fact or Fantasy? Case Report. Gastroenterology, 9, 194-199. https://doi.org/10.1159/000431307

[7] Sabbagh, C., Santin, E., Potier, A. and Regimbeau, J.M. (2012) The Superior Mesenteric Artery Syndrome: A Rare Etiology for Proximal Obstructive Syndrome. Journal of Visceral Surgery, 149, 428-429. https://doi.org/10.1016/j.jviscsurg.2012.10.003

[8] Merrett, N.D., Wilson, R.B., Cosman, P., et al. (2009) Superior Mesenteric Artery Syndrome: Diagnosis and Treatment Strategies. Journal of Gastrointestinal Surgery, 
13, 287-292. https://doi.org/10.1007/s11605-008-0695-4

[9] Unal, B., Aktaş, A., Kemal, G., et al. (2005) Superior Mesenteric Artery Syndrome: CT and Ultrasonography Findings. Diagnostic Interventional Radiology,11, 90-95.

[10] Bauer, S., Karplus, R., Belsky, V., et al. (2013) Superior Mesenteric Artery Syndrome: A Forgotten Entity. Israel Medical Association Journal, 15, 189-191.

[11] Gersin, K.S. and Heniford, B.T. (1998) Laparoscopic Duodenojejunostomy for Treatement of Superior Mesenteric Artery Syndrome. Journal of the Society of Lapraroendoscopic Surgery, 2, 281-284.

Submit or recommend next manuscript to SCIRP and we will provide best service for you:

Accepting pre-submission inquiries through Email, Facebook, LinkedIn, Twitter, etc. A wide selection of journals (inclusive of 9 subjects, more than 200 journals)

Providing 24-hour high-quality service

User-friendly online submission system

Fair and swift peer-review system

Efficient typesetting and proofreading procedure

Display of the result of downloads and visits, as well as the number of cited articles Maximum dissemination of your research work

Submit your manuscript at: http://papersubmission.scirp.org/

Or contact ss@scirp.org 